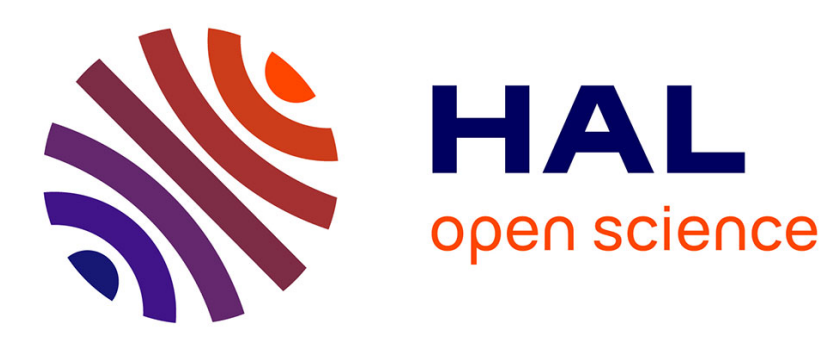

\title{
Influence of secondary phases during annealing on re-crystallization of CuInSe2 electrodeposited films
}

A. Gobeaut, Lydia Laffont, Jean-marie Tarascon, L. Parissi, O. Kerrec

\section{To cite this version:}

A. Gobeaut, Lydia Laffont, Jean-marie Tarascon, L. Parissi, O. Kerrec. Influence of secondary phases during annealing on re-crystallization of CuInSe2 electrodeposited films. Thin Solid Films, 2009, vol. 517, pp. 4436-4442. 10.1016/j.tsf.2009.01.043 . hal-00864932

\section{HAL Id: hal-00864932 \\ https://hal.science/hal-00864932}

Submitted on 23 Sep 2013

HAL is a multi-disciplinary open access archive for the deposit and dissemination of scientific research documents, whether they are published or not. The documents may come from teaching and research institutions in France or abroad, or from public or private research centers.
L'archive ouverte pluridisciplinaire HAL, est destinée au dépôt et à la diffusion de documents scientifiques de niveau recherche, publiés ou non, émanant des établissements d'enseignement et de recherche français ou étrangers, des laboratoires publics ou privés. 


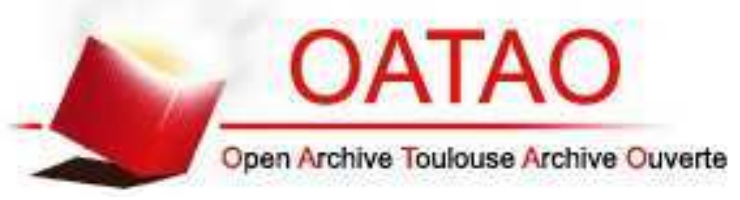

\section{Open Archive TOULOUSE Archive Ouverte (OATAO)}

OATAO is an open access repository that collects the work of Toulouse researchers and makes it freely available over the web where possible.

This is an author-deposited version published in : http://oatao.univ-toulouse.fr/ Eprints ID : 8665

To link to this article : doi:10.1016/j.tsf.2009.01.043

URL : http://dx.doi.org/10.1016/j.tsf.2009.01.043

To cite this version : Gobeaut, A. and Laffont, Lydia and Tarascon, Jean-Marie and Parissi, L. and Kerrec, O. Influence of secondary phases during annealing on re-crystallization of $\mathrm{CuInSe} 2$ electrodeposited films. (2009) Thin Solid Films, 517 (15). pp. 44364442. ISSN 0040-6090

Any correspondance concerning this service should be sent to the repository administrator: staff-oatao@ listes-diff.inp-toulouse.fr 


\title{
Influence of secondary phases during annealing on re-crystallization of CuInSe $\mathrm{C}_{2}$ electrodeposited films
}

\author{
A. Gobeaut ${ }^{\mathrm{a}}$, L. Laffont ${ }^{\mathrm{a}, *}$, J.-M. Tarascon ${ }^{\mathrm{a}}$, L. Parissi ${ }^{\mathrm{b}}$, O. Kerrec ${ }^{\mathrm{b}}$ \\ a Laboratoire de Réactivité et Chimie des Solides, 33 rue St Leu, 80039 Amiens, France \\ ${ }^{\mathrm{b}}$ Institut de Recherche et de Développement de l'Energie Photovoltaïque, 6 quai Watier, 78401 Chatou cedex, France
}

Keywords:

Solar cells

Electrodeposition

Scanning electron microscopy

Transmission electron microscopy

X-ray diffraction

\begin{abstract}
Electrodeposited CuInSe $e_{2}$ thin films are of potential importance, as light absorber material, in the next generation of photovoltaic cells as long as we can optimize their annealing process to obtain dense and highly crystalline films. The intent of this study was to gain a basic understanding of the key experimental parameters governing the structural-textural-composition evolution of thin films as function of the annealing temperature via X-ray diffraction, scanning/transmission electron microscopy and thermal analysis measurements. The crystallization of the electrodeposited CuInSe $\mathrm{f}_{2}$ films, with the presence of Se and orthorhombic $\mathrm{Cu}_{2-{ }_{x}} \mathrm{Se}\left(\mathrm{o}-\mathrm{Cu}_{2}{ }_{x} \mathrm{Se}\right.$ ) phases, occurs over two distinct temperature ranges, between $220{ }^{\circ} \mathrm{C}$ and $250{ }^{\circ} \mathrm{C}$ and beyond $520^{\circ} \mathrm{C}$. Such domains of temperature are consistent with the melting of elemental Se and the binary CuSe phase, respectively. The CuSe phase forming during annealing results from the reaction between the two secondary species $0-\mathrm{Cu}_{2}{ }_{-} \mathrm{Se}$ and $\mathrm{Se}\left(\mathrm{o}-\mathrm{Cu}_{2}-{ }_{x} \mathrm{Se}+\mathrm{Se} \rightarrow 2 \mathrm{CuSe}\right)$ but can be decomposed into the cubic $\beta-\mathrm{Cu}_{2}{ }_{x} \mathrm{Se}$ phase by slowing down the heating rate. Formation of liquid CuSe beyond $520^{\circ} \mathrm{C}$ seems to govern both the grain size of the films and the porosity of the substrate-CuInSe $e_{2}$ film interface. A simple model explaining the competitive interplay between the film crystallinity and the interface porosity is proposed, aiming at an improved protocol based on temperature range, which will enable to enhance the film crystalline nature while limiting the interface porosity.
\end{abstract}

\section{Introduction}

Silicon solar cells are still strongly leading the photovoltaic (PV) market with more than nine out of ten produced cells. Nevertheless, production of crystalline silicon is not important enough to meet the constantly growing demands from the industry. Such a shortage resulted in an important increase in the silicon price and contributed to a resurged interest in non-silicon thin film cells. Moreover, a common target for all PV industrials is to reduce the production costs while keeping decent efficiency. This proved to be successful as witnessed by the arrival of the second generation of thin film solar cells, which provide drastic improvements in terms of cost-efficiency and yields [1]. For nonsilicon thin film cells, chalcopyrite compounds $\mathrm{Cu}\left(\operatorname{In}_{x} \mathrm{Ga}_{1-x}\right)\left(\mathrm{Se}_{y} \mathrm{~S}_{1-y}\right)$ seem to be the most promising material owing to their low cost and high efficiency yields in laboratory prototypes. Yields ranging from $12 \%$ for large-scale modules ( $4000 \mathrm{~cm}^{2}$ ) to $19.9 \%$ for small-area devices [2] were achieved. Furthermore, $\mathrm{Cu}\left(\operatorname{In}_{x} \mathrm{Ga}_{1-x}\right)\left(\mathrm{Se}_{y}\right)$ modules have been produced on an industrial scale [3-4] via physical deposition processes that require high vacuum conditions resulting in high production costs. Usually, they are made by deposition of stacked elemental layers (SEL method) of $\mathrm{Cu} / \mathrm{In}(\mathrm{Ga}) / \mathrm{Se}(\mathrm{S})$ via co-evaporation or sputtering of $\mathrm{Cu}$ and

\footnotetext{
* Corresponding author. Tel.: +33 3228279 01; fax: +33 322827590 E-mail address: lydia.laffont@u-picardie.fr (L. Laffont).
}

In metallic elements followed by selenization and/or sulfurization by rapid thermal annealing leading to cells with about $12 \%$ efficiencies (Shell Solar Process) [5].

An attractive alternative approach is the two-step electrodeposition-annealing process. By slightly deviating from this process, a few laboratories have increased the material efficiency. The National Renewable Energy Laboratory (Department of Energy, U.S.A.) has, for instance, added an In co-evaporation step (or/and $\mathrm{Ga}$ ) to the process prior to annealing in order to adjust the stoichiometry of the films with the best results being the achievement of $15.4 \%$ cell efficiency [6] at a slightly higher cost owing to the extra processing step. Recently, Jost et al., working with Atotech $\mathrm{GmbH}$, performed electrodeposited precursors leading to similar reaction path as obtained in the case of the physical vapour deposition SEL method [7]. The process consists in depositing a very low amount of Se onto the precursor film during electrodeposition (Se/In ratio equal to 0.1), so as to obtain copper/ indium binary phases $\left(\mathrm{Cu}_{11} \mathrm{In}_{9}\right.$ and $\left.\mathrm{CuIn}_{2}\right)$. By doing so, the CuInSe (CISe) phase cannot be formed during the electrodeposition step but is later obtained during an annealing step carried under Se atmosphere. With this process, the binary selenide phases are formed beyond the selenium melting point $\left(221^{\circ} \mathrm{C}\right)$. After selenium transfer reactions, $\mathrm{Cu}_{2}{ }_{-} \mathrm{Se}$ and InSe are obtained, and according to the authors, these two phases react upon annealing with the elemental Se to form $\mathrm{CuInSe}_{2}$ $\left(\mathrm{Cu}_{2-x} \mathrm{Se}+2 \mathrm{InSe}+\mathrm{Se} \rightarrow 2 \mathrm{CuInSe}_{2}\right)$ [7]. In our case, the project, 
named CISEL meaning "CuInSe 2 by Electrodeposition", consists in a twostep electrodeposition-flash annealing process without any vacuum restriction in order to strongly reduce the production costs of CuInS absorbers. The versatility of this process further relies on the fact that sulfurization of the absorber is performed during annealing by previously adding a sulphur layer on the surface of the ED CuInSe ${ }_{2}$ precursors via chemical bath deposition.

Precisely, the electrodeposition step is achieved on soda lime glass-Mo substrate, and directly leads to the growth of CuInSe ${ }_{2}$ films; the latter mainly consist of the ternary chalcopyrite CISe phase together with elemental Se and Cu-Se binaries compounds. The obtained films have a low crystallinity, and secondary species are present in the entire bulk; so an annealing step is necessary after electrodeposition and chemical vaporization of sulphur on it in order to obtain films having the expected semi-conductive properties. This results in an important increase in the grains size together with the random apparition of a huge porosity near the CISeS-substrate interface that is absolutely harmful to the cells efficiency. Despite this, a cell has been made with a record efficiency of $11.3 \%$ [8], although, in order to master the porosity issue, all the mechanisms leading to the recrystallization of the films during the annealing step have to be well understood. Although a great deal of study has been done by various groups regarding the film recrystallization mechanism and the interplay between the crystalline nature of the film and its porosity, some of the fundamentals remain unknown. Hence our motivation for this thorough study that will mainly focus on the temperature-driven structural/morphology evolution of the secondary phases present in the as-made electrodeposited films. So, in order to limit the parameters of the system, the sulfurization of the precursors will not be taken into account in this study. This paper will be organized as follows: in the first part, the morphology and composition of the electrodeposited (ED) precursor will be determined and correlated with "in situ" thermal analyses; then the recrystallization of this precursor will be studied by analysis of different annealed samples, and finally a recrystallization mechanism depending on the heating rate will be put forward for ED CuInSe $e_{2}$ films.

\section{Experimental details}

\subsection{Film growing process}

\subsubsection{Electrodeposition}

One single electrodeposition step was enough to grow the CISe precursors in an acidic bath containing $\mathrm{Cu}(\mathrm{II}), \mathrm{In}(\mathrm{III})$ and $\mathrm{Se}(\mathrm{IV})$ electroactive species. These CISe films were deposited on Mo-coated soda-lime glass. The reaction of CISe formation at the cathode is described elsewhere [8]. According to thermodynamic considerations, similar secondary phases often coexist with the main CISe phase [9-10]. After electrodeposition, films are recovered from the electrolytic bath, and dried with $\mathrm{N}_{2}$ prior to being annealed. The ED process is performed either on $5 \times 5 \mathrm{~cm}^{2}$ or $30 \times 30 \mathrm{~cm}^{2}$ substrates using two different electrolysers.

\subsubsection{Annealing}

A rapid thermal process is performed in a customized halogen lamp furnace. The samples are placed onto a graphite susceptor covered with a quartz lid in order to keep a pressure of Se during annealing. The furnace is evacuated and purged with argon flow. The temperature of the process is determined using a thermocouple and a pyrometer placed above the graphite susceptor.

\subsection{Characterization}

\subsection{1. $X R D$}

X-Ray powder diffraction (XRD) patterns of the films were collected on a Scintag Diffractometer using a $\mathrm{Cu} \mathrm{K \alpha}$ radiation operating at $40 \mathrm{kV}-40 \mathrm{~mA}$ in the range $2 \theta=20-60^{\circ}$ with a $2 \theta$ step size of $0.06^{\circ}$. The temperature structural evolution of the ED films was followed by in situ XRD using a Brucker D8 Diffractometer with the CoK $\alpha$ radiation $\left(\lambda_{1}=1.78919 \AA, \lambda_{2}=1.79321 \AA\right)$, operating at $30 \mathrm{mV}$ $40 \mathrm{~mA}$ in the $2 \theta=20-70^{\circ}$ range with a $2 \theta$ step size of $0.015^{\circ}$, equipped with a Gobel mirror and a Braun PSD collector. The samples were heated in an Anton Parr Chamber HTK using a nitrogen flow, and each XRD pattern was recorded every $25{ }^{\circ} \mathrm{C}$. The ED sample had to be prepared to fit the sample holder within the chamber of the furnace; it was cut into a $1 \mathrm{~cm}^{2}$ badge, and a diamond wire reduced the thickness of the glass substrate down to $0.8 \mathrm{~mm}$.

\subsubsection{SEM/TEM}

Scanning electron microscopy (SEM) images of the film were recorded using a FEI Quanta FEG operating at $20 \mathrm{kV}$ in order to study the films morphology. Transmission electron microscopy (TEM) study was carried out with an analytical FEI Tecnai F20 ST microscope operating at $200 \mathrm{kV}$ and equipped with an Energy Dispersive Spectroscopy (EDS) analysis. Samples for electron microscopy studies were prepared by scratching the surface of the films and depositing the result onto a nickel grid coated with lacey-carbon film. The electron diffraction patterns were performed using the selected area electron diffraction (SAED) mode.

\subsubsection{Calorimetry}

Differential Scanning Calorimetry (DSC) analysis was performed on a Phoenix DSC 204 F1 set up manufactured by Netzsch. For such measurements, thin films were scratched to get the powder. The latter was inserted into an alumina crucible that was then sealed under argon atmosphere for measurement. The sample temperature was calibrated using the onset of the melting of both tin $\left(T_{\mathrm{m}}=231.88^{\circ} \mathrm{C}\right)$ and indium $\left(T_{\mathrm{m}}=156.6{ }^{\circ} \mathrm{C}\right)$ with a heating rate of $q_{\mathrm{h}}=+10^{\circ} \mathrm{C} \mathrm{min}^{-1}$. DSC experiments were systematically carried out over temperatures ranging from $20^{\circ} \mathrm{C}$ to $550{ }^{\circ} \mathrm{C}$ with a heating rate of $q_{\mathrm{h}}=+10^{\circ} \mathrm{C} \mathrm{min}^{-1}$. The heat flow was calibrated with the heat fusion of indium $\left(\Delta H=28.45 \mathrm{~J} \mathrm{~g}^{-1}\right)$.

\section{Results and discussion}

\subsection{Electrodeposited precursors}

The as-made electrodeposited films were characterized in order to determine their composition, structural characteristics and physical properties. XRD analysis of ED precursors leads to the diffractogram reported in Fig. 1a. On both sides of the molybdenum peak located at $40.6^{\circ}$ (PCPDF file $n^{\circ} 42-1120$, principal orientation (110)), there are three main Bragg peaks located in $2 \theta$ angles at $26.6^{\circ}, 44.3^{\circ}$ and $52.4^{\circ}$, which correspond to the (112), (220) and (312) planes of the CuInSe 2 chalcopyrite structure (PCPDF file $n^{\circ} 40-1487$ ), respectively [11]. Moreover, the extra Bragg peak, represented by a shoulder near the most intensive peak of CISe at $25.4^{\circ}$ corresponds to a second phase, identified by the PCPDF file $\mathrm{n}^{\circ} 47-1448$ as $\mathrm{Cu}_{2} \mathrm{Se}_{x}$, but which is more commonly reported in the literature as orthorhombic $\mathrm{Cu}_{2-x} \mathrm{Se}\left(\mathrm{o}-\mathrm{Cu}_{2-x} \mathrm{Se}\right.$ in this paper) [12]. Besides, analysis by Raman Spectroscopy performed on ED films showed the presence of elemental selenium in agreement with previous reports [13-14]. Consequently, after electrodeposition, the films not only contain the $\mathrm{CuInSe}_{2}$ phase but also one crystallized binary phase $0-\mathrm{Cu}_{2}{ }_{-} \mathrm{Se}$ and some elemental selenium.

The microstructure of the electrodeposited films, as deduced from SEM measurements (Fig. 1b), is typical of the electrodeposited CuInSe films as already reported $[15,16,17]$ regardless of both the substrate size $\left(5 \times 5 \mathrm{~cm}^{2}\right.$ or $\left.30 \times 30 \mathrm{~cm}^{2}\right)$ and the spotting shots (centre vs. edge of the substrates). The films are relatively porous with the presence of some spherical clusters (2-3 nm) at their surface; some of them being agglomerated leading to the typical cauliflower shape. Cross-section images of these films (Fig. 1c) indicate that the porosity is essentially 

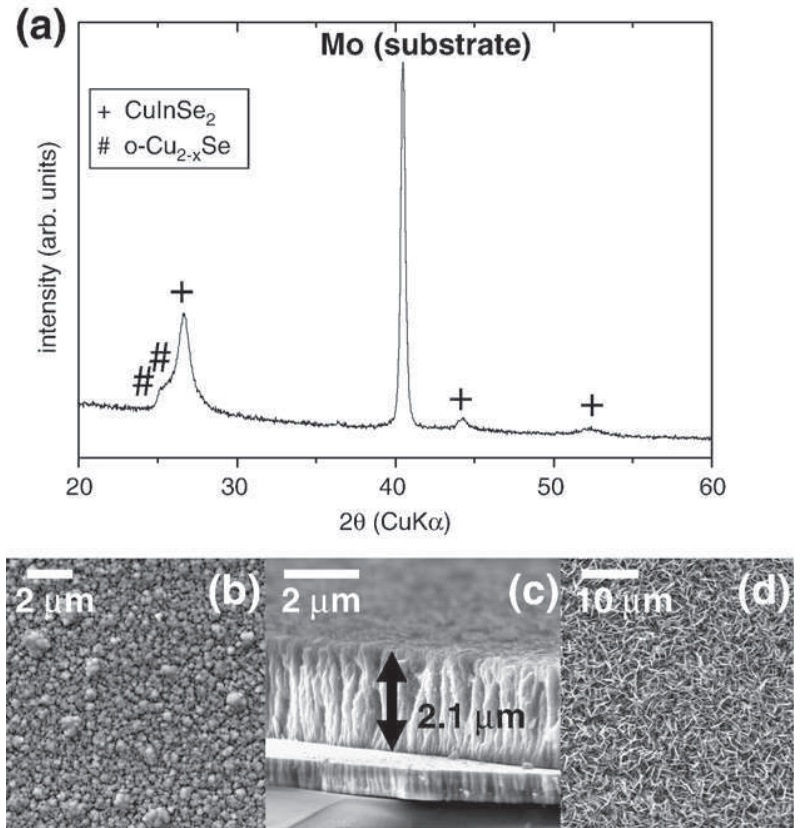

Fig. 1. (a) XRD diffractogram of electrodeposited precursor samples, (b) surface, (c) cross-section SEM pictures of an 'as-made' precursor, and (d) SEM picture of a three weeks aged ED film, the surface is completely covered with CuSe platelets.

located on the last 200-300 $\mathrm{nm}$ of the sample surface, whereas no porosity is present in the bulk of the film that is quite dense with a dendritic growth shape. Moreover, we have noted (Fig. 1d) the appearance of platelets covering parts of the surface of the films when $5 \times 5 \mathrm{~cm}^{2}$ electrodeposited films were aged in ambient atmosphere for several weeks. Interestingly, no extra XRD peak associated to these platelets could be obtained for these samples. Therefore to grasp further information on the structural/composition nature of these platelets, complementary TEM and EDS analyses were undertaken. From the SAED pattern (not shown here) we could identify the platelets as the binary phase CuSe, which composition was also confirmed by EDS analysis (ratio $\mathrm{Cu} / \mathrm{Se}$ equal to 1 ). The CuSe phase is hexagonal at room temperature ( $\alpha$-CuSe), but undergoes a structural transition into orthorhombic $\beta$-CuSe at $48^{\circ} \mathrm{C}$, and converts back to a hexagonal packing at $120{ }^{\circ} \mathrm{C}$ ( $\gamma$-CuSe) [18]. For instance, we noticed that the sample ageing appears after a shorter time for the $5 \times 5 \mathrm{~cm}^{2} \mathrm{ED}$ samples than for the $30 \times 30 \mathrm{~cm}^{2}$. Since the appearance of the CuSe platelets even occurs under nitrogen or vacuum storage conditions, it is suggested that its growth mechanism enlists a reaction between elemental Se and copper-rich binary $0-\mathrm{Cu}_{2}{ }_{-} \mathrm{Se}$ phase to give CuSe platelets $\left(\mathrm{o}-\mathrm{Cu}_{2}-{ }_{x} \mathrm{Se}+\mathrm{Se} \rightarrow 2 \mathrm{CuSe}\right)$. A great deal of study has already taken place in our group on the outcome of such phases upon annealing. Further studies on the influence of these two secondary phases $\left(\mathrm{o}-\mathrm{Cu}_{2-x} \mathrm{Se}+\right.$ elemental $\left.\mathrm{Se}\right)$ on the recrystallization process of our electrodeposited CISe films upon heating were performed. Our ED CISe films were annealed then studied by electron microscopy, X-Ray Diffraction, and thermal analysis in the hope of correlating morphology and phases transitions in order to fully decipher the recrystallization mechanism.

\subsection{Thermal evolution of ED precursors}

The thermal evolution of an ED precursor sample (recovered from a $5 \times 5 \mathrm{~cm}^{2}$ ED plate) was first studied by in situ XRD as reported in Fig. 2a. X-Ray diffractograms were collected every $25{ }^{\circ} \mathrm{C}$, and the temperature of the sample was raised to a heating rate of $6{ }^{\circ} \mathrm{C} / \mathrm{min}$ between each analysis from ambient to $550{ }^{\circ} \mathrm{C}$. For reasons of clarity, only four characteristic diffractograms are reported in Fig. 2a.
Regarding the composition evolution of the phases, the XRD pattern of the ED CISe precursor sample, having extra peaks corresponding to $0-\mathrm{Cu}_{2}{ }_{x} \mathrm{Se}$ impurity, does not significantly vary until $200{ }^{\circ} \mathrm{C}$. Therefore, for annealing temperatures greater than $200{ }^{\circ} \mathrm{C}$, the o- $\mathrm{Cu}_{2-} \mathrm{S}$ Se shoulder signal intensity progressively decreases to totally disappear near $250^{\circ} \mathrm{C}$ (Fig. 2a). No phase other than CISe was detected until $450{ }^{\circ} \mathrm{C}$, maximum temperature prior to the sample deterioration. Indeed, at higher temperatures, our data was not exploitable owing to some leakage in our high temperature chamber resulting in the formation of $\mathrm{In}_{2} \mathrm{O}_{3}$ and $\mathrm{MoO}_{2}$ as shown on the $550{ }^{\circ} \mathrm{C}$ diffractogram.

Further insight into the crystalline nature evolution of the ED films has been obtained by plotting the variation of the crystallites size ( (as deduced from the Sherrer equation using the full width at half maximum (FWHM) of the most intense CISe peak (112)) as function of temperature (Fig. 2b). Attempts to use the Williamson and Hall method to separate size from strain contributions could not be applied here owing to the two sets [(220), (204) and (312), (116)] of overlapping Bragg peaks within the CISe XRD pattern. Regardless of such a difficulty, we noticed in this figure a drastic increase in the crystalline nature of the ED film between $220^{\circ} \mathrm{C}$ and $250{ }^{\circ} \mathrm{C}$, corresponding to
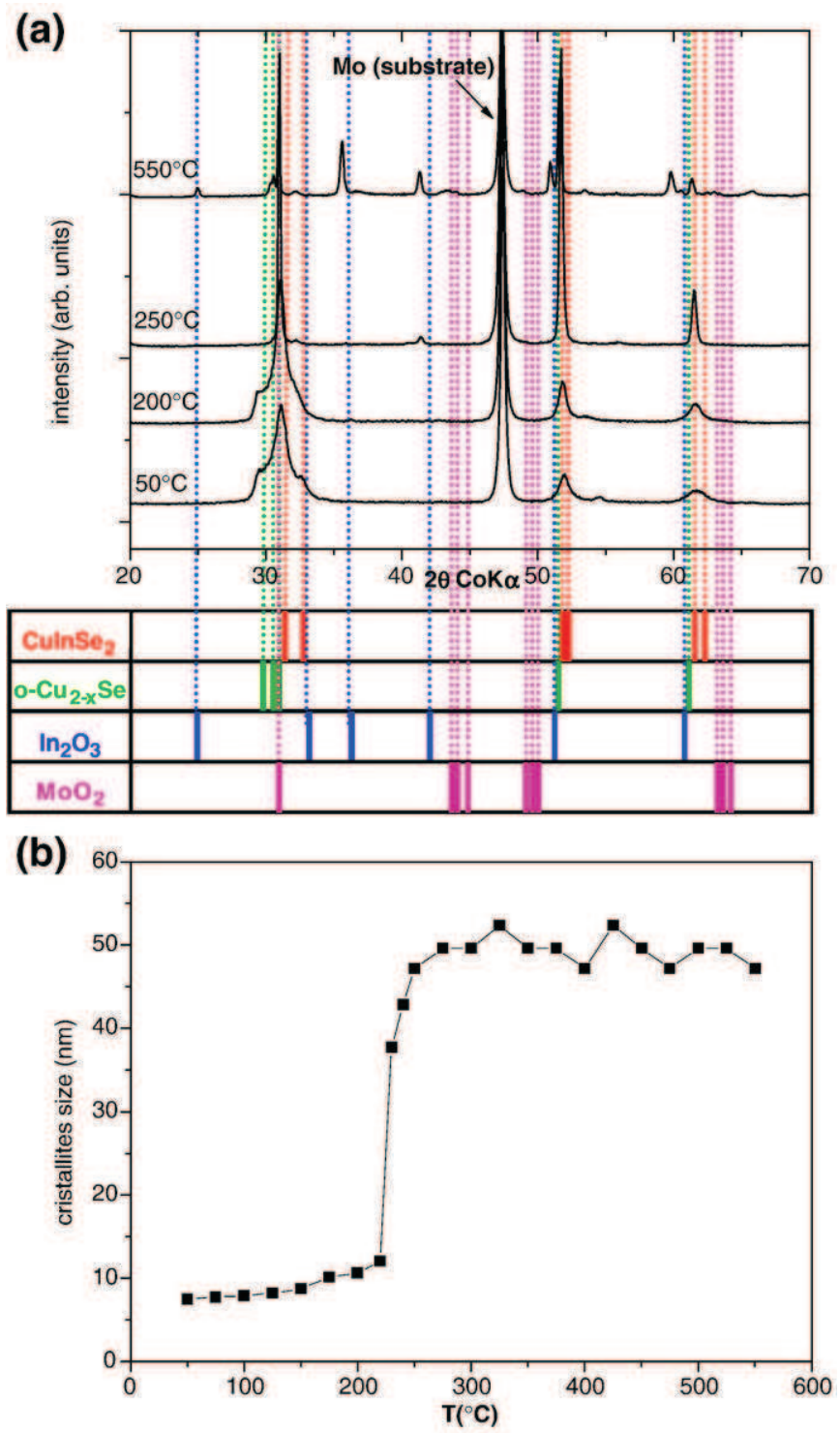

Fig. 2. (a) In situ XRD analysis on the ED precursor at $50{ }^{\circ} \mathrm{C}, 200{ }^{\circ} \mathrm{C}, 250{ }^{\circ} \mathrm{C}$, and $550{ }^{\circ} \mathrm{C}$ partially oxidized; (b) in situ analysis: crystallite size from ED film as function of temperature. 
the disappearance of the $0-\mathrm{Cu}_{2}{ }_{-} \mathrm{Se}$ signal in $\mathrm{XRD}$, and also consistent with the melting temperature of elemental Se (theoretical melting point: $221^{\circ} \mathrm{C}$ ) present in the precursor. Although we faced inherent experimental problems of oxidation for temperatures greater than $450{ }^{\circ} \mathrm{C}$, such an experiment had the merit of unambiguously indicating the occurrence of a first re-crystallization step taking place on our ED films between $220-250{ }^{\circ} \mathrm{C}$, which coincides with the melting temperature range of elemental Se (e.g.; presence of a liquid phase).

At this point, we followed, via in situ high temperature X-ray diffraction, the chemical reactivity of the secondary $0-\mathrm{Cu}_{2}{ }_{-} \mathrm{Se}$ phases and elemental Se in absence of CISe. This was done to precisely study the thermal evolution of the secondary phases present in the ED film without the presence of the CISe phase.

So, orthorhombic $\mathrm{Cu}_{2-x}$ Se has been synthesized using the same process as Haram et al. [12], which consists in putting a copper piece in an $\mathrm{H}_{2} \mathrm{SeO}_{3}$ solution $(0.1 \mathrm{~N})$. A black powdery thin layer is obtained, scrapped and then mixed with elemental selenium with a ratio $1 / 1$ corresponding to the ratio determined by Raman Spectroscopy [13-14] in ED precursors films. Four diffractograms representing the main evolution steps of the phases are reported in Fig. 3. Their evolution can be described as follows:

- From $50{ }^{\circ} \mathrm{C}$ to $150{ }^{\circ} \mathrm{C}$, the $0-\mathrm{Cu}_{2}{ }_{-x} \mathrm{Se}$ and elemental Se Bragg peaks progressively decrease while extra peaks corresponding to the CuSe phase appear.

- From $150{ }^{\circ} \mathrm{C}$ to $250{ }^{\circ} \mathrm{C}$, the ${ }_{0}-\mathrm{Cu}_{2}-x \mathrm{Se}$ and Se peaks totally disappear to the expense of both intense CuSe peaks and weak peaks corresponding to $\mathrm{CuSe}_{2}$.

- Finally, heating above $250{ }^{\circ} \mathrm{C}$ results in the total disappearance of the $\mathrm{CuSe}_{2}$ weak peaks together with a decrease in intensity of the CuSe ones because of the loss of selenium. Between $275{ }^{\circ} \mathrm{C}$ and $300^{\circ} \mathrm{C}$, all CuSe peaks have totally disappeared leading to the single cubic phase that could be either $\mathrm{Cu}_{1.8} \mathrm{Se}$ or $\mathrm{Cu}_{2} \mathrm{Se}$. Owing to both temperature dilatation issues and small lattice parameter differences between cubic $\mathrm{Cu}_{1.8} \mathrm{Se}$ (PCPDF file ${ }^{\circ} 71-0044 ; a=5.765 \AA$ ) and cubic $\mathrm{Cu}_{2} \mathrm{Se}$ (PCPDF File $\mathrm{n}^{\circ} 02-1275, a=5.731 \AA$ ), we will from now on refer to this $300{ }^{\circ} \mathrm{C}$ phase as the $\beta-\mathrm{Cu}_{2}{ }_{x} \mathrm{Se}$ with $0<x<0.2$ (PCPDF file $\mathrm{n}^{\circ} 06-0680, a=5.739 \AA$ ), in agreement with the $\mathrm{Cu} / \mathrm{Se}$ phase diagram [19].

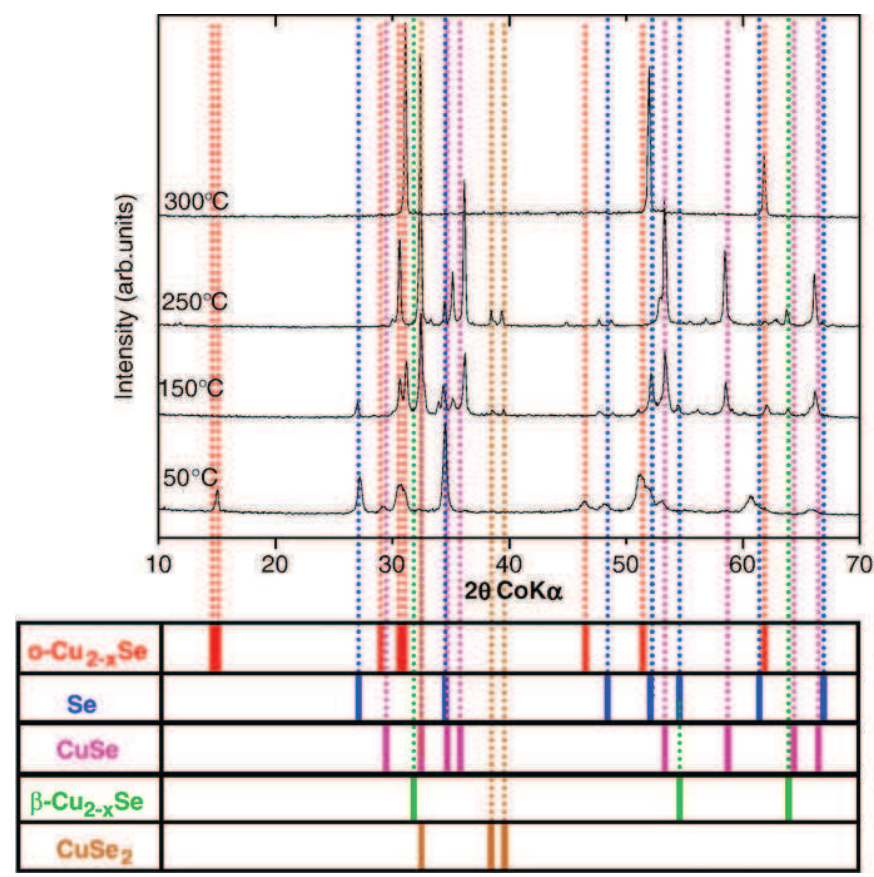

Fig. 3. In situ XRD analysis of $0-\mathrm{Cu}_{2}{ }_{x} \mathrm{Se}$ mixed with elemental selenium, at $50{ }^{\circ} \mathrm{C}$, $150{ }^{\circ} \mathrm{C}, 250{ }^{\circ} \mathrm{C}$ and $300{ }^{\circ} \mathrm{C}$
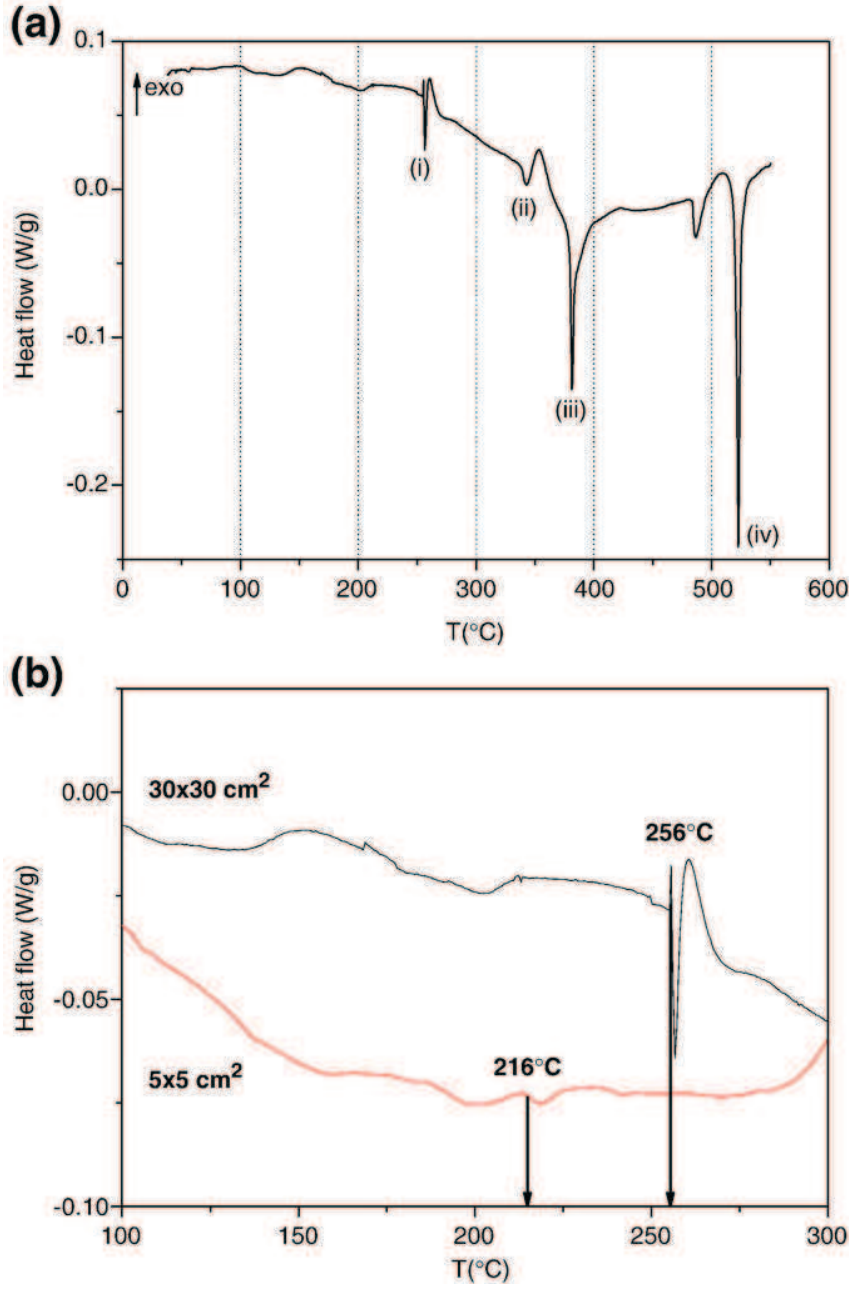

Fig. 4. (a) DSC thermogram from ED precursor powder obtained by scratching films: (i): $255{ }^{\circ} \mathrm{C}$ : Se melting (shifted), (ii): $340{ }^{\circ} \mathrm{C}: \mathrm{CuSe}_{2} \rightarrow \mathrm{CuSe}+\mathrm{Se}$ (liq), (iii): $380{ }^{\circ} \mathrm{C}$ : $\mathrm{CuSe} \rightarrow \beta-\mathrm{Cu}_{2-} \mathrm{Se}+\mathrm{Se}$ (liq), (iv): $521{ }^{\circ} \mathrm{C}$ : CuSe melting (b) DSC analysis of powder coming from $30 \times 30$ and $5 \times 5$ samples: focus on Se melting point.

Overall, from in situ XRD, we validated the chemical reactivity of o- $\mathrm{Cu}_{2-x} \mathrm{Se}$ and elemental Se to lead to the CuSe phase. Moreover, the formation of this phase starts at low temperature (from $75{ }^{\circ} \mathrm{C}$ appearance of peaks of CuSe from XRD). In light of this observation we can conclude that the appearance of CuSe platelets on ED precursors after ageing is due to the low temperature reactivity of ${ }_{0}-\mathrm{Cu}_{2}{ }_{-} \mathrm{Se}$ with Se. Besides, we also spotted at higher temperature $\left(>250{ }^{\circ} \mathrm{C}\right)$ the growth of $\beta-\mathrm{Cu}_{2}{ }_{x} \mathrm{Se}$ phase resulting from the decomposition of the CuSe phase associated to the loss of Se.

To further support the above scenario, DSC measurements were performed on powders resulting from scratching one $30 \times 30 \mathrm{~cm}^{2}$ electrodeposited precursor film. Four main defined peaks corresponding to endothermic processes are observed (Fig. 4a). The first one (denoted (i)) although shifted from $221{ }^{\circ} \mathrm{C}$ to $255^{\circ} \mathrm{C}$ is most likely due to elemental selenium trapped within the CISe films. Interestingly, for comparison, DSC analysis of $5 \times 5 \mathrm{~cm}^{2}$ samples shows no shift of the Se melting peak (Fig. 4b). This difference in thermal behaviour could also account for the differences in ageing behaviour observed for $30 \times 30 \mathrm{~cm}^{2}$ and $5 \times 5 \mathrm{~cm}^{2}$ samples; knowing from our experience that the electrodeposition step leads to more free elemental selenium in the case of the smallest samples than for the $30 \times 30 \mathrm{~cm}^{2}$ ones. Furthermore, the weak intensity of the Se melting peak for the $5 \times 5 \mathrm{~cm}^{2}$ powder can be explained by its easier partial consumption due to the formation of CuSe as previously shown from in situ XRD. So, the more accessible elemental Se is, the easiest it is to form CuSe; this 


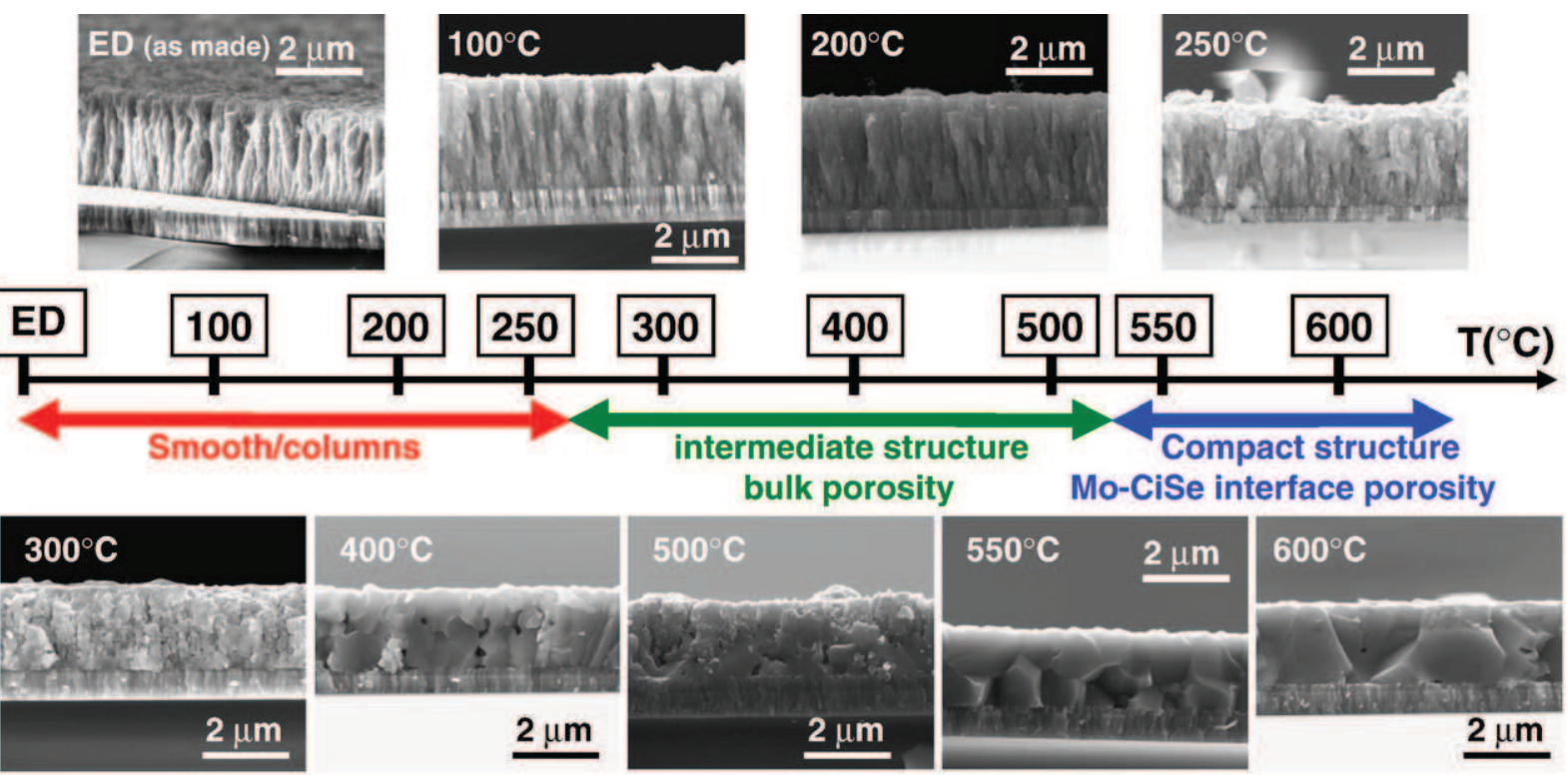

Fig. 5. SEM cross-section pictures from ED precursors annealed at different temperatures (heating with a step of 10 min reached with a 2 min heating ramp for each temperature).

explains the differences in intensity of the Se melting endothermic peak between the $5 \times 5 \mathrm{~cm}^{2}$ and $30 \times 30 \mathrm{~cm}^{2}$ samples.

Going back to the DSC analysis, a few endothermic peaks are observed at higher temperatures, with namely a second one (ii) at $340^{\circ} \mathrm{C}$ due to the decomposition of $\mathrm{CuSe}_{2}$ ((ii): $\mathrm{CuSe}_{2} \rightarrow \mathrm{CuSe}+\mathrm{Se}_{\text {liq. }}$ ), and a third one (iii) at $380{ }^{\circ} \mathrm{C}$ associated to the CuSe partial decomposition following the reaction $2 \mathrm{CuSe} \rightarrow \beta-\mathrm{Cu}_{2-x} \mathrm{Se}+\mathrm{Se}_{\text {liq. }}$ [20]; this agrees with our previous in situ XRD measurements, which have shown the growth of $\beta-\mathrm{Cu}_{2-x}$ Se between $275{ }^{\circ} \mathrm{C}$ and $300{ }^{\circ} \mathrm{C}$ (Fig. 3). These two reactions lead to the formation of liquid Se which could benefit the CISe re-crystallization by acting as a constant flux.

Finally, the last endothermic peak near $521{ }^{\circ} \mathrm{C}$ corresponds to CuSe melting (theoretical melting point: $524^{\circ} \mathrm{C}[19]$ ). However, it should be mentioned that the DSC analysis is carried out in a sealed crucible, meaning that no loss of selenium occurs whereas in an open space the decomposition of the CuSe phase is irreversible due to the loss of selenium during the process. This implies that the decomposition of CuSe would lead to the formation of $\beta-\mathrm{Cu}_{2}{ }_{-} \mathrm{Se}$. So, the $\left[\mathrm{Cu}_{\left.2-{ }_{x} \mathrm{Se}\right] /}\right.$ [CuSe] ratio in a sample heated above $380^{\circ} \mathrm{C}$ is strongly dependent on the heating rate. The slower the heating rate is, the more $\beta-\mathrm{Cu}_{2}{ }_{-} \mathrm{Se}$ will be formed. Furthermore, this $\beta-\mathrm{Cu}_{2-}$ Se phase has a high melting point of $1113{ }^{\circ} \mathrm{C}$, which would be unreachable for our process, meaning that this phase would stay trapped in the bulk in the solid state and could not participate in the increase in the CISe grain size. So, a fast annealing ramp is necessary to re-crystallize the sample in order to avoid a loss of selenium in the copper-selenide binary compounds, and to keep the CuSe phase in the film till its melting point at $524^{\circ} \mathrm{C}$ (Fig. 4b).

Last, we should mention the existence of an extra endothermic peak, near $480{ }^{\circ} \mathrm{C}$, which cannot be accounted with respect to the phase transitions supposed to occur in our system. In light of the In-Se binary phases diagram [19], a possible reaction to explain this extra peak would be the fusion of $\mathrm{In}_{3} \mathrm{Se}_{4}$ occurring near $500{ }^{\circ} \mathrm{C}$, but XRD analysis have been unsuccessful to support this hypothesis.

\subsection{Annealed samples}

To check the informations deduced from the aforementioned in situ analyses of the ED precursors, an ex situ study of samples annealed on the halogen lamps furnace was undertaken. $2.5 \times 2.5 \mathrm{~cm}^{2}$ sample specimens cut out of a $30 \times 30 \mathrm{~cm}^{2}$ ED sample were annealed according to the following temperature protocol: it consists of a heating ramp of 2 min to various temperatures ranging from $100{ }^{\circ} \mathrm{C}$ to $600{ }^{\circ} \mathrm{C}$ followed by a $10 \mathrm{~min}$ annealing step at the selected temperature. Afterwards, the cross-section of the resulting annealed samples was observed by SEM (Fig. 5). The collected SEM images show the temperature-driven thin film morphology evolution that can be classified in three categories; each corresponding to a specific annealing temperature range.

- For annealing temperatures up to $250^{\circ} \mathrm{C}$, the columnar structure of the ED CISe thin films is preserved.

- Annealing treatments ranging from 300 to $500{ }^{\circ} \mathrm{C}$ lead to an intermediate film structure with the presence of porosity both at the surface and in the bulk of the film. While the sample annealed at $300{ }^{\circ} \mathrm{C}$ is quite porous, samples annealed at higher temperatures $\left(400{ }^{\circ} \mathrm{C}\right.$ and $\left.500{ }^{\circ} \mathrm{C}\right)$ present larger particle sizes and are denser, but still contain porosity within their core.

- Finally, further annealing to $550{ }^{\circ} \mathrm{C}$ and $600{ }^{\circ} \mathrm{C}$ results in compact films having therefore some porosity essentially located near the Mo-CISe interface.

Additionally, hexagonal-shaped crystals were observed on the surface of the samples annealed between $100{ }^{\circ} \mathrm{C}-300^{\circ} \mathrm{C}$ (Fig. $6 \mathrm{a}-\mathrm{SEM}$ picture), and analyzed by TEM (Fig. 6b). From the selected area electron diffraction pattern (Fig. 6c) we could deduce that these crystals correspond to the $\gamma$-CuSe phase (PCPDF file $n^{\circ} 27-0185$ ) in

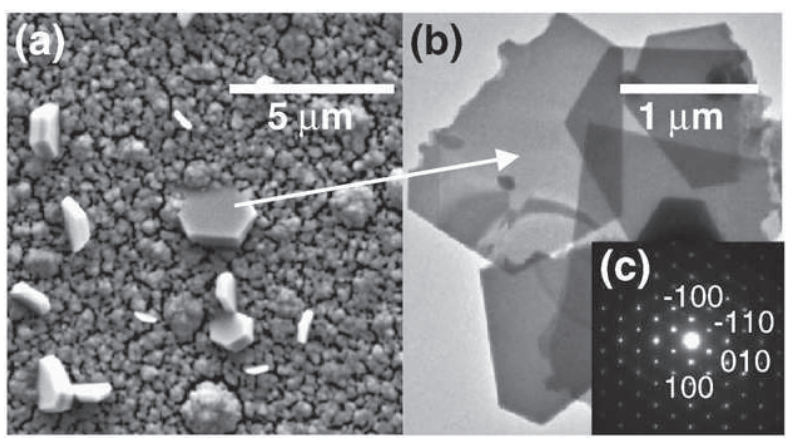

Fig. 6. (a) SEM picture of $330^{\circ} \mathrm{C}$ annealed sample surface showing the presence of CuSe crystals; (b) Bright field TEM picture, and (c) SAED pattern of one CuSe crystal. 
agreement with EDS analysis that has revealed a $\mathrm{Cu} / \mathrm{Se}$ ratio of 1 , and consistent with DSC measurements that have shown that the CuSe phase does not decompose until $380^{\circ} \mathrm{C}$.

The annealed samples were also studied by XRD, and their diffractograms are reported in Fig. 7a. The shoulder at $25.4^{\circ}$, located near the (112) CISe principal peak and corresponding to the binary $0-\mathrm{Cu}_{2-x} \mathrm{Se}$ phases observed on ED precursors, is still present until $250{ }^{\circ} \mathrm{C}$, but vanishes at higher temperatures concomitantly with a sharpening of the main Bragg peaks corresponding to the CISe phase. Although SEM has revealed the presence of CuSe crystals, no extra peak due to the CuSe phase could be detected, implying that the formation of CuSe on the surface is very localized and punctual. In order to qualitatively track the temperature-driven crystalline evolution of our samples, the FWHM of the principal CISe peak $\left(26.6^{\circ}\right.$, (112) plane) was determined for each annealed sample and plotted in Fig. 7b. Although we are well aware that caution should be exercised in over-interpreting such Bragg peak widths, which also depend on particle size and strains, we can deduce with full confidence that, like for the morphology, the crystalline evolution of the samples upon annealing is step-wise with the most prominent increase being observed for annealing tempera-

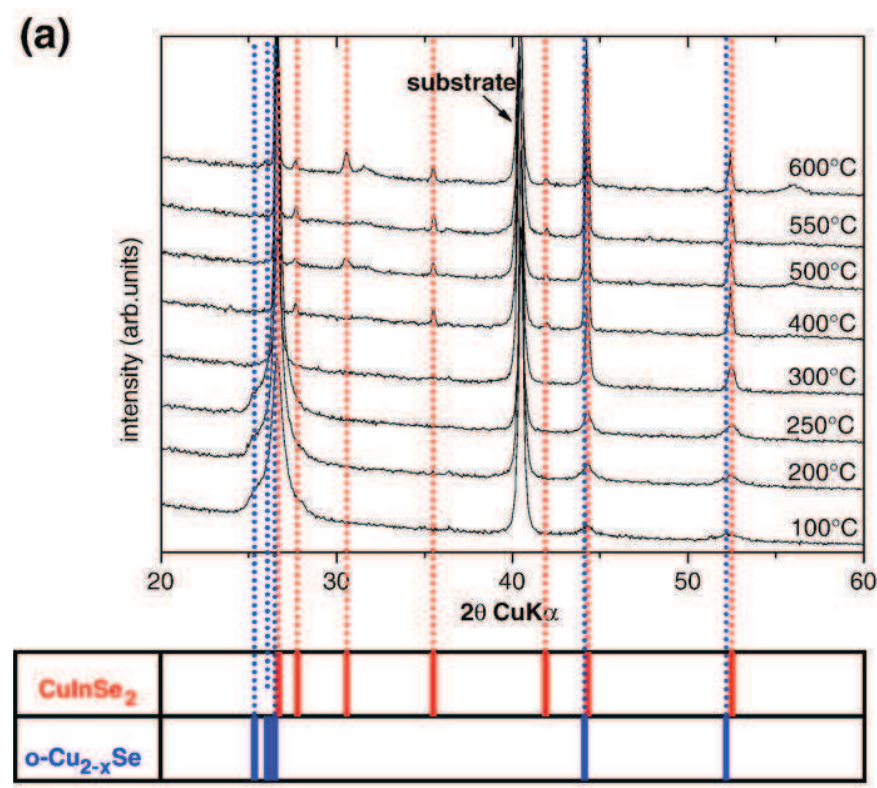

(b)

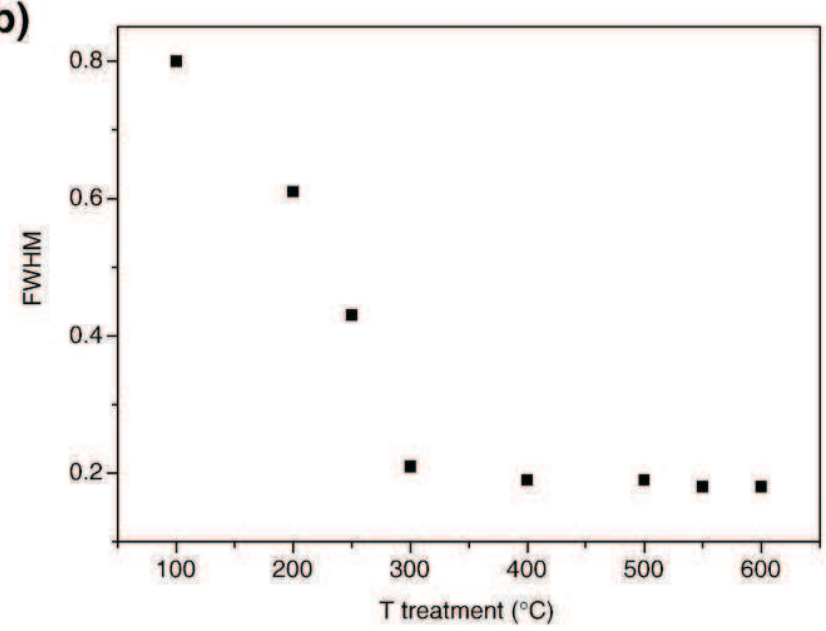

Fig. 7. (a) XRD of ED precursors annealed at different temperatures (same heating conditions as Fig. 5); (b) Full width at half maximum (FWHM) of the (112) main CuSe peak as function of the annealed temperature. tures ranging from $250{ }^{\circ} \mathrm{C}$ to $300{ }^{\circ} \mathrm{C}$. The onset of such a crystallite coarsening in this temperature domain nicely fits with the melting of Se that was shown to occur near $250^{\circ} \mathrm{C}$, as deduced by DSC (Fig. 4a), for a $30 \times 30 \mathrm{~cm}^{2}$ sample. Finally, no noticeable changes in the coarsening of the particles were revealed for annealing temperatures greater than $300{ }^{\circ} \mathrm{C}$. In contrast a spectacular morphology change, leading to massive grains (e.g., material densification), was observed between 500 and $550{ }^{\circ} \mathrm{C}$. This range of temperatures can obviously be related to the melting of CuSe occurring at $524{ }^{\circ} \mathrm{C}$.

\subsection{Recrystallization mechanism}

The above results have shown that the crystallinity and morphology of the CISe ED precursors containing $0-\mathrm{Cu}_{2}{ }_{-} \mathrm{Se}$ and elemental Se phases can be tuned over two well-determined domains of temperature. The first one from $220^{\circ} \mathrm{C}$ to $300{ }^{\circ} \mathrm{C}$, which involves the melting of elemental Se, enables to act on the crystalline nature of the CISe film while the second one, near $520{ }^{\circ} \mathrm{C}$ and corresponding to the melting point of CuSe, enables the coarsening and the densification of the main phase. However, some differences were noted in the film crystallinity/morphology evolution depending on the history of the treated film (freshly made vs. aged films) and the type of annealing procedure being used (thermal vs. flash heating). Such an observation directly implies the influence of slow vs. fast annealing on recrystallization of the films as discussed next.

Let's first consider freshly made films:

- For slow annealing rate (Fig. 8a), the melting of Se at $221{ }^{\circ} \mathrm{C}$ enables an enhancement of the crystalline nature of the CISe film as proven by the increase in the crystallites size between $230{ }^{\circ} \mathrm{C}$ and $250{ }^{\circ} \mathrm{C}$ as deduced by "in situ" XRD analysis. But afterwards, owing to the peritectoidic reaction ( $2 \mathrm{CuSe} \rightarrow \beta-\mathrm{Cu}_{2-x} \mathrm{Se}+\mathrm{Se}_{\text {liq. }}$ ) occurring at $377{ }^{\circ} \mathrm{C}$, the elemental selenium is progressively removed from the film. Consequently, the initial binary phase o$\mathrm{Cu}_{2-} \mathrm{Se}$, which is transformed into $\mathrm{CuSe}$, then decomposes and converts into a poor selenide $\beta-\mathrm{Cu}_{2}{ }_{x} \mathrm{Se}$ phase, therefore preventing the $520^{\circ} \mathrm{C}$ grain-coarsening step associated to CuSe.

- On the contrary, when annealing is fast, either via Infrared lamps or operated in closed environment (like in DSC measurements) (Fig. 8b), selenium loss is minimized so that the two successive enhancements of the crystallites and grains size forming the CISe films can occur. The first one, still due to Se melting, enables to enhance the crystallite growth (e.g.; sample crystallinity), while the second one, associated to the melting of the CuSe phase near $521{ }^{\circ} \mathrm{C}$, as deduced from DSC measurements, favours grain coarsening. In short, fast annealing (or closed space annealing) avoids selenium loss of the film so that the CuSe compound is formed and its melting promotes the formation of compact and massive films with the presence of porosity near the Mo-CISe interface.

In contrast with the freshly made films, we have shown that the ageing of CISe leads to the formation of CuSe platelets owing to the chemical reactivity of $0-\mathrm{Cu}_{2}{ }_{x} \mathrm{Se}$ with elemental Se at room temperature. In such a case, as before and even more so when the annealing is too slow, the existing CuSe phase is totally decomposed, and cannot contribute to the enhancement of the grain size observed near $520^{\circ} \mathrm{C}$. Hence the advantage of using a fast rating process for the aged films as well.

All these information enable to suggest the recrystallization mechanism reported on Fig. 8 distinguishing between slow and fast annealed samples for either freshly made or aged CISe samples. Thanks to this mechanism, we can define a heating protocol involving the two aforementioned liquid phases while producing CISe deposits with minimized porosity. Owing to the greatest conversion yield associated with the presence of sulphur within the CISe films, we are presently revisiting the above mechanism when sulphur is deposited 
(a)

\section{Slow annealing}

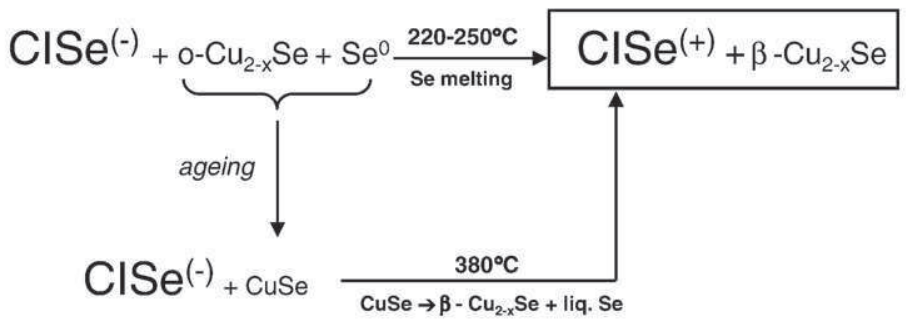

(b)

\section{Fast (or closed space) annealing}

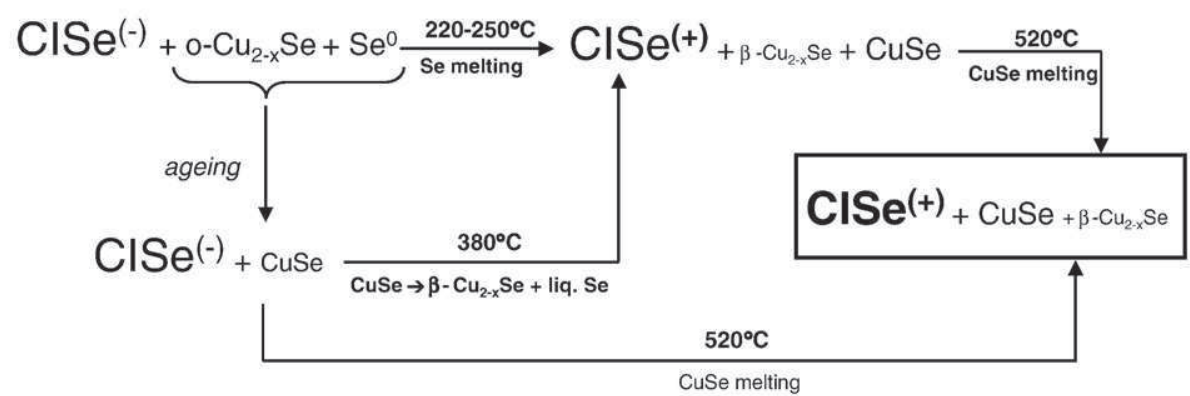

Fig. 8. Recrystallization mechanism: for (a) slow annealing and (b) fast (or close space) annealing. The font size illustrates the relative amount of each phase in the film: the larger the font the higher the fraction of that phase in the film. Bold face characters indicates grain size enlargement. The level of crystallinity of the CuInSe 2 phase is noted by $(-)$ low and $(+)$ high.

as a thin layer on top of the CISe films or when CISe films are annealed under a sulphur-containing atmosphere.

\section{Conclusion}

We have reported the influence of the $0-\mathrm{Cu}_{2}{ }_{-} \mathrm{Se}$ and Se secondary phases on the re-crystallization process of ED CISe films. We showed this re-crystallization process to be governed by the existence of two liquid phases ( $\mathrm{Se}$ at $221{ }^{\circ} \mathrm{C}$ and $\mathrm{CuSe}$ at $524{ }^{\circ} \mathrm{C}$ ) that act as a flux to promote crystallite or grain size coarsening, respectively, and whose appearance is strongly dependent on the annealing process. Fast heating, which leads to the successive appearance of the Se and CuSe phases, is preferred to low heating, which solely leads to liquid Se and solid that decompose into $\beta-\mathrm{Cu}_{2}{ }_{-} \mathrm{Se}$ and Se prior to reaching the CuSe melting temperature. The presence of the liquid Se phase is mandatory to enhance the crystalline nature of the film while the presence of a CuSe liquid film is necessary for an optimization of the grain size, but unfortunately, it comes with an important increase in the porosity near the Mo-CISe interface. Future work will aim to determine the influence of the crystalline nature, grain size and porosity of the ED CISe films on their semi-conductive properties so as to produce CISe solar cells with high conversion yields. Due to the determination of the re-crystallization mechanism, we might be able to both adjust the electrodeposition parameters as well as the heating ramp in order to facilitate the presence of $\mathrm{CuSe}$ or $\beta-\mathrm{Cu}_{2}{ }_{-} \mathrm{Se}$ as well.

\section{Acknowledgements}

We gratefully acknowledge O. Ramdani, C. Van-de-Putte, P.P. Grand and P. Panheleux from the IRDEP for the synthesis of the electrodeposited precursors and the annealing of the samples. The authors also gratefully acknowledge A. Finke from the LRCS for the differential scanning calorimetry measurements and the ANR (Allocation Nationale de Recherche) for the funds.

\section{References}

[1] M.A. Green, Sol. Energy 76 (2004) 3.

[2] I. Repins, M.A. Contreras, B. Egaas, C. Dehart, J. Scharf, C.L. Perlins, B. To, R. Toufi, Prog. Photovolt. Res. Appl. 16 (2008) 235.

[3] M. Powalla, B. Dimmler, Sol. Energy Mater. Sol. Cells 75 (2003) 27.

[4] A. Goetzberger, C. Hebling, H.W. Schock, Mater. Sci. Eng. R40 (2003) 1

[5] J. Palm, V. Probst, F.H. Karg, Sol. Energy 77 (2004) 75.

[6] R.N. Bhattacharya, W. Batchelor, K. Ramanathan, M.A. Contreras, T. Moriarty, Sol. Energy Mater. Sol. Cells 63 (2000) 367.

[7] S. Jost, F. Hergert, R. Hock, J. Schulze, A. Kirbs, T. Voß, M. Purwins, Sol. Energy Mater Sol. Cells 91 (2007) 1669.

[8] D. Lincot, J.F. Guillemoles, S. Taunier, D. Guimard, J. Sicx-Kurdi, A. Chaumont, O. Roussel, O. Ramdani, C. Hubert, J.P. Fauvarque, N. Bodereau, L. Parissi, P. Panheleux, P. Fanouillere, N. Naghavi, P.P. Grand, M. Benfarah, P. Mogensen, O. Kerrec, Sol. Energy 77 (2004) 725.

[9] L. Thouin, J. Vedel, J. Electrochem. Soc. 142 (1995) 2996.

[10] S. Massaccesi, S. Sanchez, J. Vedel, J. Electrochem. Soc. 140 (1993) 2540

[11] Powder Diffraction File, Joint Committee on Powder Diffraction standards (JCPDS), ASTM, Philadelphia, PA, 1997.

[12] S.K. Haram, K.S.V. Santhanam, M. Neumann-Spallart, C. Lévy-Clément, Mater. Res. Bull. 27 (1992) 1185.

[13] O. Ramdani, J.F. Guillemoles, D. Lincot, P.P. Grand, E. Chasseing, O. Kerrec, E. Rezpka, Thin Solid Films 515 (2007) 5909.

[14] V. Izquierdo-Roca, A. Pérez-Rodríguez, A. Romano-Rodríguez, J.R. Morante, J. Álvarez-García, L. Calvo-Barrio, V. Bermudez, P.P. Grand, O. Ramdani, L. Parissi, O. Kerrec, J. Appl. Phys. 101 (2007) 103517.

[15] R.P. Raffaelle, T. Potdevin, A.F. Hepp, S.G. Bailey, Mater. Sci. Semicond. Process. 2 (1999) 289.

[16] J. Kois, S. Bereznev, E. Millikov, A. Öpik, Thin Solid Films 511-2 (2006) 420.

[17] S. Taunier, J. Sicx-Kurdi, PP. Grand, A. Chomont, O. Ramdani, L. Parissi, P. Panheleux, N. Naghavi, C. Hubert, M. Ben-Farah, J.P. Fauvarque, J. Connolly, O. Roussel, P. Mogensen, E. Mahé, J.F. Guillemoles, D. Lincot, O. Kerrec, Thin Solid Films 480-1 (2005) 526.

[18] A.L.N. Stevels, F. Jellinek, Recl. Trav. Chim. Pays-Bas 90 (1971) 273.

[19] H. Okamoto, J. Phase Equilib. Diffus. 25 (2004) 201.

[20] D. Wolf, G. Müller, Thin Solid Films 361-2 (2000) 155. 